\title{
Effects of blood pressure control in cardiovascular prevention
}

\author{
Nathan Artom ${ }^{1}$, Alessandra Vecchié ${ }^{1}$, Aldo Pende ${ }^{1}$
}

${ }^{1}$ Clinic of Internal Medicine 1, Department of Internal Medicine, University of Genoa School of Medicine. IRCCS Azienda Ospedaliera Universitaria San Martino-IST Istituto Nazionale per la Ricerca sul Cancro, 6 viale Benedetto XV, 16100 Genoa, Italy.

Corresponding author: Nathan Artom, MD, Department of Internal Medicine, University of Genoa School of Medicine. IRCCS Azienda Ospedaliera Universitaria San Martino-IST Istituto Nazionale per la Ricerca sul Cancro, 6 viale Benedetto XV, 16100 Genoa, Italy.

Phone number: +393480025220

Mail: nat.artom@hotmail.it

Running title: Blood pressure and cardiovascular prevention.

Keywords: hypertension, pathogenesis, arterial stiffness, antihypertensive drugs, residual risk, blood pressure control.

Conflict of interest: None.

Word count: 6980 words.

Character count: 39446 characters. 


\begin{abstract}
High blood pressure is the main risk factor worldwide for mortality and morbility. Subjects with uncontrolled hypertension increased in the last decades. This narrative review focused its attention on the diagnosis, the pathophysiology, the clinical consequences of arterial hypertension, and on the factors that must be considered for a better blood pressure control. Essential hypertension is caused by a complex interaction of genetic factors, modiulation of homeostatic systems, vessel wall modification, inflammatory mediators. The best therapeutic choice can be, in daily clinical practice, challenging due to the various classes of available drugs, the different individual responses to the same antihypertensive drug, the variability of the phenotypes. The review will also discuss the best strategy to reduce cardiovascular events in hypertensive patients targeting either the overall cardiovascular risk or to blood pressure levels only. This review is based on the material searched for and obtained via MEDLINE and PubMed up to March 2016. The search terms used were "hypertension, blood pressure control" in combination with "pathophysiology, lifestyle, arterial stiffness, antihypertensive drugs, target values and comorbidity”.
\end{abstract}




\section{Introduction}

Arterial hypertension $(\mathrm{AH})$ represents the main risk factor worldwide for cardiovascular $(\mathrm{CV})$ and all-cause mortality and is strongly correlated to the risk of stroke, myocardial infarction (MI), renal and heart failure [1]. AH prevalence increases with age involving one third of Western population and $70 \%$ of adults $\geq 70$ years [2]. Further, despite a series of International Guidelines provides adequate support to the physicians, subjects with uncontrolled hypertension have been increasing over the last years [3-7]. This is in part due to population aging and to the increase in the prevalence of obesity [2]. Aim of this narrative review is therefore to begin with the pathogenetic mechanisms of $\mathrm{AH}$, highlighting emerging issues such as arterial stiffness and inflammation , and understanding how can be individualized excellently antihypertensive therapy, providing a useful tool for the clinician to obtain the therapeutic goal. The control of BP also at a population level will be discussed.

The Prospective Studies Collaboration (PSC) was a large meta-analysis of 61 observational studies on the association between BP and vascular mortality and performed between 1950 e 1990. It was based on 100,000 deaths among 1 million subjects without a history of vascular disease [8]. The main finding was a continuous log-linear association between BP and vascular mortality (coronary artery disease, stroke) irrespective of the baseline BP value, but with a diminishing association with aging: for every $20 \mathrm{mmHg}$ lower systolic BP (SBP), the hazard ratio (HR) for death from CAD declined from 0.49 in subjects aged $40-49$ to 0.67 in those aged $80-89$ years [8]. The PSC and the Framingham Heart Study also showed that SBP was a stronger predictor of CV events (CVEs) than diastolic BP (DBP) [9]. About pulse pressure (PP) several data showed its predictive role of CVEs, particularly in elderly subjects [10]. Further, about BP as a predictor of CVEs all large epidemiological studies had found no differences between male and female and subjects of different ethnicities [2]. 


\section{Pathophysiology of hypertension}

Hypertension is a very complex disease with a multifactorial pathophysiology, which combine genetic factors, lifestyle, neuro-hormonal disorders, arterial stiffness, low-grade inflammation. In a simplified view, BP may be considered the product of cardiac output $(\mathrm{CO})$ and peripheral resistance (PR). CO is the result of the fluid volume (preload) and the contractility of the heart. Hypertension occurred when $\mathrm{CO}$ and/or PR increased. The latter is a simplified version of the pathogenesis but also useful, as we described below, to understand its finer pathogenetic mechanisms.

\section{Genetic factors}

One of the aspects to investigate in hypertensive subjects is the presence of $\mathrm{AH}$ also in relatives. This fact confirm a genetic contribution to BP levels, with a role of multiple genes. Several studies found the presence of high $\mathrm{BP}$ as a part of family history in $60 \%$ of subjects [11]. In last years several studies investigated the presence of genetic polymorphism in human hypertension, also with the aim to predict the response to any given therapy. For example, Sciarrone [12] and co-workers showed that subjects with $\alpha$-adducin Gly460 $\rightarrow$ Trp polymorphism had a brilliant response to diuretic but not the other pharmacological classes. The International Consortium for Blood Pressure Genome - Wide Association Studies provided a genetic risk score based on 29 independent genetic variants. This score is associated with BP levels and TOD [13]. A very recent meta-analysis identified 34 genes associated to high BP levels [14]. Furthermore, some companies sell genetic test to identify individuals with genetic variants associated with, for example, an overactivation of the renin-angiotensin system (RAS) and that can consequently help in choosing the most suitable drug. However, today this is not applied in clinical practice because of the high costs. Currently, the research for hypertension genes is still developing and requires new and complex studies. The hope is to use gene therapy in the management of hypertension as a part of the antihypertensive therapy [15]. 


\section{Lifestyle: sodium intake and obesity}

The sodium restriction in population is an important target for CV prevention, because sodium intake is positively associated with BP [16]. The mechanism involved many pathways, and has not been completely understood [17]. Certainly, a high sodium intake increases sodiemia and the subsequent volume-dependent BP level. Several studies analyze the sodium intake in different population across the world [18, 19]. The INTERrnational study of SALT and blood pressure (INTERSALT) studied salt intake in 52 population samples of 32 countries using 24-urinary specimens [18]. The 24-hour sodium excretion ranged from a minimum of 0,46 grams per day (g/d) in some remote population groups like Yanomami Indians to 5,6 g/d revealed in North China. The INTERrnational study of MAcro/micronutrients and blood Pressure (INTERMAP) confirmed these findings and underlined regional differences in sources of sodium intake: in the United Kingdom and in the United States the most dietary sodium comes from processed food, instead in China the principal source of sodium is the salt added to cooking [19].

Many cohort studies reported a positive association between sodium intake and BP levels [20]. The Prospective Urban Rural Epidemiological (PURE) study showed an increase in SBP for each $1 \mathrm{~g}$ increase in sodium intake [20]. Furthermore, the increase in BP values varied depending on the baseline of sodium assumption. In accord with these findings, there was a reduction in SBP associated with a reduction in sodium intake, and this reduction was more significant in patients on high sodium diet [20]. Subjects can be divided in sodium sensitive, those who have with dietary sodium reduction a greater fall in BP, TOD and CVE, and sodium resistant. The first group presented low-renin levels, such as blacks or elderly subjects [21]. Many clinical trials evaluated the effect of sodium reduction on BP. One of the most noticeable, the Trial of HypertensiOn Prevention (THOP), conducted in North America, stressed the difficult to keep a low salt consumption and that over time there is an attenuation of the antihypertensive effect of sodium reduction [22]. However, several studies demonstrated the association between reduction in salt intake and incidence of CVEs and CV mortality. There is a large variability in results coming from prospective cohort studies, 
ranged from a positive association between salt assumption and CVEs, null association and an inverse $\mathrm{J}$-shaped association, with an increased risk in population with low sodium intake [23]. However, in Western population, sodium restriction is a key system for reducing BP levels and CVEs, without risk of J-shaped association because of the high content of sodium in processes food. Finally, authors suggest a target of sodium intake of 3-5 g/d. This is the range where subjects reach the better reduction of $\mathrm{BP}$ and the lowest rate of CVEs. The 24-hour sodium excretion is useful indicator of sodium intake: above $100 \mathrm{mmol}$ per day indicate an excess of sodium intake. However, authors underlie that the key sources of excess sodium are processed food. The future of a correct sodium consumption is a process that involves food industry, which is the major responsible for the increase in sodium intake in Western populations.

Excess weight gain is a major cause of $\mathrm{AH}$ and it is associated with $\mathrm{CV}$ and metabolic disease. Several studies conducted evidenced a linear association between BMI, and BP levels [24, 25]. The Framingham Offspring Study showed that overweight and obesity were responsible for $78 \%$ of essential hypertension in men and $65 \%$ in women [26]. Conversely, weight loss decreased BP levels [27]. Many factors influenced the relationship between obesity and AH. The BP control is much difficult the longer the duration of obesity. Another important aspect is the distribution of the fat. In fact, visceral and retroperitoneal fat are stronger associated with hypertension [28]. Although these clinical evidences, the pathophysiology of obesity-associated hypertension is not completely understood. Visceral adiposity determines a physical compression on the kidneys resulting in an increase in intrarenal pressure with an alteration of renal natriuresis [29]. Visceral obesity is also associated with a RAS iperactivation. Furthermore, in obese patients there is an increase in sympathetic activity and a decrease in parasympathetic tone [30, 31]. Finally, if overweight is maintained during several years, it can cause chronic kidney disease, which worsen hypertension and may eventually cause treatment-resistance [32, 33]. 


\section{The sympathetic Nervous System activaction}

The Sympathetic Nervous System (SNS) has an important role in the regulation of CV homeostasis. Several studies showed the association between SNS activation and increased resting heart rate and CV risk [34.]. Hypertensive subjects with a SNS overdrive presented a higher norepinephrine plasma concentration than normotensive subjects [35, 36]. Further, Mancia and co-workers with the norepinephrine spillover method, which involved the infusion of small doses of radiolabeled norepinephrine, demonstrated the increase in norepinephrine release from the adrenergic nerve terminals of these subjects $[35,36]$, and allowed to quantify the regional norepinephrine spillover, particularly in the heart and the kidney. Adrenergic mediators are also involved in arteriolar remodeling and are responsible of the increase in peripheral resistance [37, 38]. SNS overactivation is an early event in the history of $\mathrm{AH}$, and may precede the hypertensive state [39]. In addition, the SNS overactivity is more frequent in young hypertensive subjects: this finding supports the concept that adrenergic overdrive may precede the development of the essential hypertension [35, 36]. Hypertensive patients with excessive TOD in relation to their BP levels and hypertension duration often showed a great sympathetic overdrive [40,41], suggesting that an hyperadrenergic state may accelerate the progression of CVD.

Based on the evidence discussed above, authors underlined that SNS overdrive has a role in the development, maintenance and progression of $\mathrm{AH}$ and could represent a primary target of pharmacologic and non-pharmacologic treatments. However, no clinical trial demonstrated the effect on mortality of decreasing adrenergic activity in $\mathrm{AH}$ [42].

\section{The renin-angiotensin system}

In recent years, the central role of the RAS has been emphasized [43]. The excessive production of renin determines an overstimulation of AT1 receptors, resulting in hypertensive effects. The major action attributed to AT1 activation are vasoconstriction, increase of reactive oxygen species and activation of cytokines and growth factors (see below the section "Role of inflammation in 
hypertension") [43]. By contrast, AT2 receptors counteracted these effects [44]. To choose the best drug treatment, some authors suggest to subclassify subjects with AH in RAS-dependent essential hypertensive (high-normal renin levels) and volume-dependent hypertensive (low renin levels) [45]. The distinction between the two subtypes in clinical practice is not carried out by the dosage of renin levels (which may depend on ongoing therapy or other factors), but on the basis of clinical features of the patient. Further, the dosage of renin in essential hypertension is not costeffectiveness and difficult in clinical practice [46]. However, RAS-dependent hypertension presents an increased sympathetic nervous system tone and is common in anxious young subjects or in people with a medical history of alcoholism, sleep apnea, acute stroke, sinus tachycardia, paroxysmal hypertension [45]. Mann and colleagues suggested in these subjects to add, if high BP levels are still present after a two drugs regimen (a traditional association RAS inhibitor + Antivolume), as third drug a beta-blocker or an alfa-blocker. Conversely, volume dependent hypertension is presented in subjects with high sodium intake, presence of edema, high body surface area, chronic kidney disease. In these subjects, these author suggested, in addition to the association RAS inhibitor + Anti-volume, to optimize the dose of the diuretic and eventually add as third drug spironolactone [45]. This mechanistic approach has not been transposed by International Guidelines but provides essential ideas at least for drug choice in the treatment of uncontrolled hypertension. In addition, Mann's point of view is useful to underline the importance of the activation of the RAS system in the pathogenesis of hypertension.

\section{Arterial stiffness and central BP: emerging factors to understand the pathogenesis of hypertension}

Arterial stiffness, which is emerging as a novel marker of subclinical arteriosclerosis, is expression of hardening (arteriosclerosis) of large arteries (primarily, aorta) due to abnormal collagen production and reduced amount of elastin, with consequent stiffening and thickening of the arterial wall $[47,48]$. The gold standard to measure arterial stiffness is carotid-femoral pulse wave velocity (cfPWV), a noninvasive exam that measures aortic stiffness with applanation tonometry [49]. The 
relationship between arterial stiffness and hypertension can be very complex: an increased baseline PWV is associated independently with disrupting effects on aortic elastin but, on the other hand, SBP increases aortic wall stress with an accelerated elastin degradation [50]. Although data from the Framingham Heart Study support the hypothesis that aortic stiffness may precede hypertension, other studies have found a relationship between baseline SBP and progression of PWV [51]. Since cfPWV increases with ageing and with higher BP levels, reference values were recently published [52]. The latest 2013 European Society of Cardiology (ESC)/European Society of Hypertension (ESH) guidelines for the management of Arterial Hypertension stressed the importance of cfPWV as a marker of subclinical vascular disease and confirmed a threshold value of 10 meter/second [3]. Many studies showed the independent role of cfPWV as a predictor of all-cause and CV mortality also in the general populations $[53,54]$. Normally, aorta works as a diastolic pump which ensure a functioning tissue perfusion throughout the cardiac cycle. With stiffness, aorta lose its distensibility, and most of the stroke volume flows through the arterial system and peripheral tissue during systole. As a consequence, the flow becomes intermittent with excessive flow and pressure pulsatility during systole [55]. Further, in $\mathrm{AH}$ there are alterations also in small arteries: vasoconstriction, increased wall-to-lumen ratio and vessels rarefaction, with a consequent increase in total peripheral resistance and mean BP [56]. The final result is a large/small artery cross-talk: the higher mean BP increases large artery stiffness which leads to high central BP (CBP) and PP. As a vicious circle, the increased aortic stiffness in turn damages small resistance vessels [57]. With a heart beat a pulse wave travels forward in the circulation and generates multiple reflected waves which travel retrograde toward the heart. The composite reflected wave (sum of multiple tiny reflected waves) impacts the shape of the aortic pressure wave, which is the result of the sum of forward and backward wave. When PWV is elevated, the reflected wave return early in systole and CBP consequently increases [58]. As for cfPWV, even for CBP were validated reference values [59]. CBP seems to be a greater predictor of CVEs events than brachial pressure and some authors proposed the measure of CBP in clinical routine as a guide for therapeutic choice [60]. The Conduit 
Artery Functional Evaluation (CAFE) Study first showed the clinical relevance of CBP: subjects randomized to calcium channel blocker $(\mathrm{CCB})$ or to beta-blockers presented the same peripheral $\mathrm{BP}$ levels. By contrast, the first group showed a significant reduction in CBP and a significant less number of CVEs when compared to the second group (see also the below section "BP lowering drugs beyond BP targets and role for combination therapy") [61]. In addition, if a large metaanalysis [62] did not show a significant additive predictive value of CBP beyond brachial pressure $(\mathrm{P}=0.057)$, other data demonstrated that the measure of CBP determines a better management of the hypertensive patient [63] and that CBP strongly correlated with TOD than brachial BP [64]. However, up to now, International Guidelines do not recommend routine CBP measurements in clinical daily practice $[3,4,5,6]$. CBP could exert an important role in isolated systolic hypertension in youth, where an elevated PP amplification could lead to elevated brachial SBP with normal CBP. There is no evidence that these subjects could benefit of antihypertensive treatment [3].

\section{Role of inflammation in hypertension}

Recent evidences stress the role of inflammation in hypertension [65]. As mentioned above, one of the effect of AT1 activation is the increase of inflammation with an excess of oxidative stress [65]. Several animal studies provided interesting data. The B7/CD28 $\mathrm{T}$ cell costimulation axis, which interacts with CD86 expressed on dendritic cells, is required for full activation of T lymphocytes [66]. The treatment of angiotensin II-induced hypertensive mice with an inhibitor of the axis lowered BP, and B7 deficient mice are resistant to BP elevation in response to angiotensin II [66]. Further, hypertensive mice presented an increased expression of CD86 in dendritic cells [67]. Other authors found in angiotensin II-induced hypertension an increased in aortic monocytes/macrophages and of markers inflammations such as vascular cell adhesion molecule-1, cyclooxygenase 2 , nitric oxide synthase [68]. The accumulation of $\mathrm{T}$ cells and macrophages in experimental hypertension is predominant in the kidney and in the vessels, anatomic sites critical to the genesis and the 
maintenance of $\mathrm{AH}$ [69]. Finally, emerging data showed also a role for neutrophils in hypertension [70]: very recently Liu and co-workers showed in a cohort of 28,850 adult Chinese subjects that elevated baseline neutrophil to lymphocyte ratio significantly increased the risk of developing hypertension [71].

Figure 1 schematically summarize the pathogenesis of hypertension.

\section{Blood pressure measurement. Office values, home or ambulatory blood pressure monitoring: which is the best?}

One of the major topic discussed in hypertension research is the difference between the different methods for BP measurement. If International Guidelines continue to considered office BP measurements the gold standard for the diagnosis of $\mathrm{AH}[3,4,5,6]$, several data and expert consensus provided interesting information on the important role of home $\mathrm{BP}$ and of ambulatory $\mathrm{BP}$ monitoring (ABPM), also for the prediction of CVEs [72]. In fact, ABPM can give information on the day/night $\mathrm{BP}$ cycle, the BP variability, the presence of white coat hypertension (WCH) or masked hypertension (MH) [72]. For these reasons, several trials such as the Systolic Hypertension in Europe (SYST-EUR) study [73], performed in patients with isolated systolic hypertension, the Dublin Outcome Study [74], and the Pressioni Associate Monitorate E Loro Associazioni (PAMELA) Study [75] showed that ABPM had a closer relation to CVEs than office BP values. About the day/night BP cycle, non-dippers subjects, probably for the more load of BP on the heart and the vessels, compared to dippers subjects, presented a more frequent occurrence of TOD and CVEs [75]. Further, Dublin Outcome Study and the PAMELA Study showed that the same increase in SBP values determined an increased CV mortality, when occurred during night, suggesting a superior prognostic role of absolute night-time BP values with respect to day-time BP values [74, 75]. The risk increases even more in riser subjects: as the night-day ratio rises the CVEs increase. In extreme dipper subjects no sufficient data are available to determine a possible prognostic role [3]. 
$\mathrm{BP}$ variability, which increases with age and correlates with the mean BP level, depends on behavioural (for example, anxiety, job stress) and non-behavioural factors. Abnormal BP variability (in particular, nocturnal BP variability) is associated with presence of TOD and with an increased of CVEs and CV mortality [76]. The PAMELA study demonstrated that the short-term erratic or residual BP changes that contribute to overall 24-hours BP variability, in addition to its cyclic component (day-night and postprandial variations) have a significant relationship with CV and allcause mortality [75].

$\mathrm{ABPM}$ and home BP measurement are fundamental for the diagnosis of $\mathrm{WCH}$ and $\mathrm{MH}[77,78]$. $\mathrm{WCH}$ is a condition with a prognosis less worse than $\mathrm{MH}$ or sustained hypertension but that is important to diagnose and that should not be equated to the condition and the prognosis of normotensive subjects [75]. Both $\mathrm{WCH}$ and $\mathrm{MH}$ are associated with an increased metabolic risk such as diabetes and overweight and with an increased risk of TOD [77]. WCH has a prevalence of $9-16 \%$ and is associated with age, female sex and non-smoking. Subjects with WCH presented an increased risk of developing sustained hypertension and a CV risk greater than normotensives [75]. $\mathrm{MH}$ has a prevalence of $13 \%$ and is associated with younger age, male sex, smoke, alcohol, physical activity, anxiety, job stress. Subjects with MH present an increases CV risk closer to that of sustained hypertension than to WCH or normotension [78].

Despite these observations, ESC/ESH Guidelines for the managemant of AH consider office BP the gold-standard for screening, diagnosis and management of hypertension and indicate the out-ofoffice measurement in limited circumstances (for example, suspicion of $\mathrm{WCH}$ or $\mathrm{MH}$, suspicious of true and false resistant hypertension) [3]. By contrast, the National Institute for Health and Clinical Excellence (NICE) guidelines suggests, if office BP is high, to offer ABPM to confirm the diagnosis of AH. Further, if a person is unable to tolerate ABPM, HBPM is a suitable method [5]. The 2015 Canadian Hypertension Education Program Recommendations for Blood Pressure Measurement, Diagnosis, Assessment of Risk, Prevention, and Treatment of Hypertension (CHEP) recommends for the diagnosis of hypertension office $\mathrm{BP}$ values $\geq 180(\mathrm{SBP})$ and/or $110 \mathrm{mmHg}$ 
(DBP). Out-of-office BP measurements (if possible, ABPM) should be performed if in the first visit mean office BP measurement is 140-179 (SBP) $\mathrm{mmHg}$ and/or 90-109 $\mathrm{mmHg}$ (DBP) [6].

Authors suggest, for the diagnosis and the management of $\mathrm{AH}$, based on International Guidelines, expert consensus, cross-sectional and longitudinal studies, to add to office BP measurements at least home BP measurements. If there is the suspicious of abnormal night-time values or increased BP variability considering $\mathrm{ABPM}$ as soon as possible. However, it is also important to underlie that the reproducibility of ABPM is quite low, and one ABPM is not a sufficient to classify with certainty the night-time BP ratio and/or the BP variability of a subject [72].

\section{Blood pressure lowering drugs: effects beyond target values and role for combination therapy}

RAS inhibitors are the recommended first-line drugs in Caucasian subjects [3]. Diuretics played a major role in Afro-American hypertensive subjects, because their $\mathrm{AH}$ is generally a volumedependent hypertension [4]. In elderly subjects with isolated systolic hypertension CCB and/or diuretic are the most effective in reducing SBP [3]. Beyond BP values, in the early 2000s, four trials provided the best evidence in favor of a particular drug-regimen: the Losartan Intervention For Event reduction Trial (the LIFE Trial) [79], the Valsartan Antihypertensive Long-term Use Evaluation trial (VALUE) [80], the Anglo-Scandinavian Cardiac Outcomes Trial (ASCOT) [81] and the Avoiding Cardiovascular events through COMbination therapy in Patients LIving with Systolic Hypertension trial (ACCOMPLISH) [82]. These trials showed a different number of CVEs in different drug-regimen groups despite no difference in brachial BP values between groups. In the LIFE Trial [79], 9,193 hypertensive patients were randomized to losartan or atenolol. Hydrochlorothiazide was added in the majority of patients to achieve BP control. After an average follow-up of 5 years the composite primary CV endpoint was reduced by $13 \%$ in the losartan group. The major benefit was seen in stroke which was reduced by $25 \%$. In the VALUE trial [80], 15,245 hypertensive patients were randomized to either valsartan, or amlodipine. Hydrochlorothiazide was added to each arm in attempting to achieve goal BP targets. Mean follow-up was 4.2 years. BP were 
more effectively and more rapidly reduced in the amlodipine-based treatment arm. Although the primary composite endpoint of cardiac morbidity and mortality was similar in the two arms of the trial, MI and stroke occurred less frequently in the amlodipine-based treatment arm (risk reduction $19 \%$ and $15 \%$, respectively). In the ASCOT-BP trial [81], over 19,000 hypertensive patients with no prior history of CAD were randomized to amlodipine or atenolol. The ACE-Inhibitor perindopril or the diuretic bendroflumethiazide was added to each arm, respectively, in an attempt to achieve BP targets. After an average follow-up of 5.5 years, the trial was stopped prematurely because of highly significant outcome benefits in favor of the amlodipine-based regimen. All CVEs were reduced by $26 \%$, stroke by $23 \%$, and all-cause mortality by $11 \%$ by the amlodipine-based regimen. In the fourth trial, ACCOMPLISH [82], 11,506 hypertensive patients were randomized to a combination of the benazepril, with either hydrochlorothiazide, or amlodipine. Patients were followed for 3 years. CVEs were reduced by $20 \%$ (MI by $22 \%$ and stroke by $16 \%$, respectively) in benazepril/amlodipine arm compared with the benazepril/hydrochlorothiazide. These different in the primary outcomes are in part due to a better effect on $\mathrm{CBP}$ of a specific drug regimen, as the CAFE study (an ASCOT substudy) showed [61]. However, the cumulative evidence from these trials strongly supports the view that, in hypertensive patients, combination therapy with or $\mathrm{ARB} / \mathrm{CCB}$ is likely to be associated with better $\mathrm{CV}$ outcomes and that ACE-I/CCB combinations are preferable to ACE-I/diuretic combinations on major $\mathrm{CV}$ endpoints. The above recommendations apply, in general, to those subjects with uncomplicated hypertension. In hypertensive subjects with associated $\mathrm{CV}$ disease such as heart failure or CAD, the guidelines are consistent in recommending specific drugs with compelling indications $[83,84]$.

In resistant hypertension, other trials showed that the addition of spironolactone to the association of RAS inhibitor + CCB + diuretic is more effective than the addition of an alpha-blocker or a betablocker [85]. However, in all the cases of essential hypertension, several data suggested to start with a combination therapy [86]. The combination therapy provides an increased achieve of BP target, a synergistic effect of the drug combination, a reduction rate of side effects with also an increased 
therapeutic adherence [3]. Further, in recent years a single pill contains two or three antihypertensive drug, with another reason of increased adherence in subjects in combination therapy [87]. A large meta-analysis [88] confirmed these considerations, and recently Gradman and co-workers showed the reduction rate in CVEs in subjects who started a combination therapy [89]. The reduction in CVEs was attributable to a more rapid achievement of target BP.

The results of the main cited trials of this section are summarize in Table 1.

\section{Adherence to therapy and new treatments}

Non-adherence to therapy is one of the major cause of inadequate BP control in patients diagnosed with resistant hypertension [90]. The unrecognized of patients with falsely uncontrolled BP (pseudo-resistance) is very important. In fact, in case of noncompliance with the antihypertensive therapy clinician may requests additional expensive diagnostic test [91]. Furthermore, subjects poor concordant with therapy have an higher $\mathrm{CV}$ risk [92]. A recent meta-analysis reported a lower adherence in patients treated with diuretics and $\beta$-blockers [93]. Also the prescription of a large number of antihypertensive drugs is a possible cause for noncompliance [94]. Several methods have been suggested to evaluate the prevalence of non-adherence to treatment, including self-reporting questionnaires, electronic monitoring systems, pills counting and, in recent years, measurement of serum or urine drug concentration using liquid chromatography-mass spectrometry [95, 96]. Some of them, such as electronic records of pill box opening, do not prove the real drug intake and are less useful in clinical practice [97]. In a recent study [98] authors used the measurement of serum antihypertensive drug concentrations to test the concordance with treatment in two groups of patients diagnosed with resistant hypertension; the first group is composed of hospitalized patients, the second of outpatients. The non-adherence was surprisingly elevated, in particular in the second group in which accounted for almost 50\%. Two other studies tested the adherence by toxicological urine analysis on samples collected on the day of the clinical visit $[99,100]$. The complete nonadherence was respectively of $30 \%$ and $25 \%$. BP values were higher in nonadherent patients. Direct 
urine or serum analysis have two important limitations: the technique in not available for all antihypertensive drugs and the method is relatively expensive (about 40-60 euro). However, investigations for secondary forms of hypertension or new interventional treatments have a greater cost. Lastly, even the noncompliance per se has a cost in terms of population's health.

For these reasons, physicians must have lot of attention to the problem of non-adherence, and it may be important to use motivational strategies such as involving patients in making decision, suggesting the use of HBPM, reducing the number of drugs with the single pill associations.

Neprilysin, a neutral endopeptidase, degrades the brain natriuretic peptide (BNP), the urodilatin and the atrial natriuretic peptide (ANP). For these reasons, Neprilysin may be an important target in the treatment of $\mathrm{AH}$ [101]. Indeed neprilysin inhibition cause an increase in natriuretic peptides plasma levels and a subsequent vasodilation, natriuresis, reduction of adrenergic overdrive and of RAS activity, antiproliferative and antihypertrophic effects on vasculature and heart [102]. In AH treatment is useful to associate the neprilysin inhibitor with a RAS blocker or an endothelinconverting enzyme inhibitor because neprilysin also degrades vasoconstrictor peptides. This association can lead to vasodilatation and natriuresis by reducing at the same time the vasoconstrictor effects [103]. LCZ696 is the first dual-acting agent composed of the association between neprilysin inhibitor prodrug AHU377 and valsartan. In a randomized, double-blind, placebo-controlled trial, LCZ696 was compared with valsartan and AHU377 in 1328 patients with mild to moderate hypertension. LCZ696 produced a significantly greater reduction in BP values than valsartan; AHU377 produced a BP reduction significantly greater than placebo but smaller than LCZ696. In the Phase III Prospective Comparison of angiotensin receptor-neprilysin inhibitor with ACEI to Determine Impact on Global Mortality and Morbidity in Heart Failure (PARADIGM-HF) trial was compared the efficacy and safety of enalapril and LCZ696 in 8442 patients with class II, III or IV heart failure [104, 105]. This randomized double-blind trial underlined the superiority of LCZ696 in reducing BP, CV death and hospitalization. In the LCZ696 group there was also more reduction in mean SBP. The US Food and Drug Administration approved Entresto (Novartis), 
sacubitril plus Valsartan, on July 2015 for the treatment of chronic heart failure [106].

Catheter-based renal denervation (RDN) is an interventional treatment proposed for resistant hypertension, considering the role of SNS activity in elevation of BP [42]. In 2009, the nonrandomized study (Symplicity HTN-1) showed a significant reduction in BP after the RDN [107]. The following Symplicity HTN-2 confirmed these results [108]. The BP reduction was durable, lasting over 36 months of follow-up [109, 110]. However, these two trials had some limitations: they were not blinded (vulnerability to patient and physician related biases), and the evaluation of efficacy, was based on office rather than ABPM [111]. ABPM, as mentioned above, reduces observer bias and minimizes the white-coat effect. Further, drug adherence was not monitored, either at baseline or during follow-up. The subsequent Symplicity HTN-3 was a singleblind randomized trial in order to prove the efficacy of the RDN in resistant hypertension [112]. Otherwise, Symplicity HTN-3 failed to reach the primary end point. Lack of demonstrated efficacy of RDN in Symplicity HTN-3 may be due to lack of statistical power or that the a fraction of African American participants increased their antihypertensive medication, contrary to protocol, which masked a potential BP lowering effect of RDN in contrast to other participants. In addition, as a consequence of the inexperience of the investigators, the denervation procedure was inaccurate in many cases due to insufficient delivery of appropriate energy in the renal arteries. The Prague-15 study was a very recent and rigorous study. This prospective, randomized, open-label multicenter trial evaluated the efficacy of RDN versus intensified pharmacological treatment including spironolactone in patients with true-resistant hypertension. This was confirmed by 24-hour ABPM after and by measurement of plasma antihypertensive drug levels. One-hundred six patients were randomized to renal denervation $(n=52)$, or intensified pharmacological treatment $(n=54)$. Both the arms of the study showed a significant and similar reduction in BP levels [113]. Further studies are needed to better understand the mechanism and the efficacy of renal denervation.

The prospective non randomized DEBut-HT trial studied the early generation of implantable device for the electrical stimulation of the carotid sinus baroreceptors [114]. This trial studied 45 subjects 
with resistant hypertension and showed a significant and prolonged reduction in office BP and in ABPM. 8 serious adverse events (7 procedure-related and 1 device-related) occurred. A secondgeneration system of BAT (Barostim neo ${ }^{\mathrm{TM}}$ ) has been recently designed with the aim to reduce the operating field and hence possible complications. A single (instead of 5) electrode is implanted at one carotid site, and the battery is smaller, with an extended life span $(\approx 3$ years). In a single-arm open-label study enrolling 30 patients with resistant hypertension a significant BP reduction was observed after 6 months. Only 1 long-term procedure-related complications occurred [115]. Future studies will better clarify the role of stimulation of the carotid sinus baroreceptors in resistant hypertension.

\section{Blood pressure control: the earlier and the lower are the better? Importance of residual risk}

The management of hypertensive subject should be "BP oriented" or "risk factors oriented"? The treatment of the hypertensive patient should be modulated only according to BP levels or in relation to overall $\mathrm{CV}$ risk? International Guidelines for the management of AH appear to follow the first approach, providing BP thresholds (generally $\leq$ 140/90) that the patient must reach $[3,4,5,6]$. However, guidelines for raised blood cholesterol suggest a "risk factors oriented" approach, and the treatment is based on the overall CV risk, calculated, for example, with the European SCORE charts [116, 117]. Further, in their meta-analysis, the Blood Pressure Lowering Treatment Trialists' (BPLTTC) conclude that the "risk factors oriented" method based on CV risk calculators is more cost-effectiveness than the BP approach [118]. However, Zanchetti and co-workers, in a recent meta-analysis based on 68 randomized controlled trials, provided some interesting considerations [119]. As BPLTTC, they showed that relative reductions of all outcomes did not significantly differ in groups at different $\mathrm{CV}$ risk and absolute risk reductions significantly increased with the increasing level of $\mathrm{CV}$ risk, suggesting the cost-effectiveness of risk-based approach. However, key appears to emphasize that break down BP levels of high-risk individuals will not prevent the fact that these same individuals, because of their high residual risk, will present a larger number of 
CVEs when compared to low-risk subjects [119]. This concept leads to make three important considerations. First, the best achievement in terms of prognosis is obtained by treating the subjects with mild hypertension without risk factors ("the earlier the better"). Second, at any level of CV risk, lower BP levels are better ("BP oriented" approach: the lower the better). Third, it is important to identify the residual risk of subjects by evaluating the presence of TOD to reclassify their CV risk and to modulate the drug therapy. Hence the importance of assess the presence of TOD in subjects with AH. The hypertensive patient should be evaluated for the presence of vascular organ damage (arterial stiffness), carotid damage (increased intima-media thickness (IMT, presence of atherosclerotic plaques), heart damage (left ventricular hypertrophy, systolic dysfunction, diastolic dysfunction, silent ischemia) [3]. However, these exams have costs and is a major challenge for the clinician to select patients for TOD evaluation. Recently, Struthers proposed the B-type natriuretic peptide (BNP) screening as a cost efficient system to identify hypertensive patients with residual risk [120]. The identification of patients with residual risk is important for drug regimen choice. For example, an hypertensive subjects without TOD can benefit (as mentioned in the above section) as a first-line drug of RAS inhibitor [3]. By contrast, the presence of a systolic dysfunction requires the addition of other drug classes such as beta-blockers [121].

Very recently, the Systolic blood PRessure INtervention Trial (SPRINT) convincingly support the concept "the lower the better". The SPRINT study randomized 9,361 hypertensive subjects with at least one $\mathrm{CV}$ risk factor (not diabetes) and older than 50 years to a "intensive" treatment group, designed to reach a SBP target $<120 \mathrm{mmHg}$, and a "protocol" group, designed to reach a SBP target $<140 \mathrm{mmHg}$. The study stopped early because of the superior benefits of the "intensive" treatment group on CVEs, CV mortality and total mortality, suggesting new SBP target, different from those proposed by International Guidelines $[122,123]$. Several data of this study merit to be discussed. The results of SPRINT on "hard" endpoint could potentially change all the future Guidelines on AH. Heart failure was the most common CVE, and by contrast there was no difference between two groups on the incidence of stroke. This is in contrast with all the large 
longitudinal trials on hypertension which have been demonstrated that the strongest $\mathrm{CV}$ outcome related to hypertension is stroke. This could be attributable to the fact that the study stopped early, and some CVEs such as stroke have not had time to emerge. Hypotension, syncopal episodes, acute kidney injury, and serum electrolyte abnormalities were more commonly detected in the "intensive" treatment group, but certainly not so commonly as to cancel out the major observed benefits.

The limitations of the study were the average run-in BP in SPRINT (averaging, $139.7 \mathrm{~mm} \mathrm{Hg}$ ), with a contingent modest BP fall to-target in the "intensive" treatment group (18 $\mathrm{mm} \mathrm{Hg})$ and the exclusion of diabetic and frail patients. For the same reasons this trial did not add knowledge about BP target to reach in high-risk individuals such as diabetics. The Action to Control Cardiovascular Risk in Diabetes Blood Pressure trial (ACCORD BP), which used the same SBP goals used in SPRINT to determine the value of intensive compared with standard BP reduction in 4,733 diabetic adults, showed that the composite CVD outcome was $12 \%$ lower in the intensive treatment group, but not statistically significant [124]. Another limitation of SPRINT is that the subjects enrolled in the study were more "fit" than those who, for example, live in nursing homes, so the trial did not provide information on BP thresholds in frail patients with lots of comorbidities [125]. Finally, although SPRINT results probably will radically change the future guidelines, this study has some severe limitations, and the clincian must individualize the BP goals taking into account all the patient's characteristics.

Finally, several studies have identified BP levels below which CVEs increase rather than decrease. In the medical literature, this phenomenon has been called J curve: as above certain levels increase CVEs plungers, this also happens when BP is too low [126]. The attention was especially focused on DBP, the main factor underlying coronary perfusion. However lots of studies included subjects with CV disease, and some of these found a J-shaped curve also for DBP and stroke and for SBP and CAD [127]. In conclusion, up to date, down SBP values between 90 and $114 \mathrm{mmHg}$ and DBP values between 60 to $74 \mathrm{mmHg}$ there is no evidence to suggest a J-shaped. In conclusion, further studies, also performed in diabetic and in frail subjects, are needed to improve medical knowledge 
on hypertension and definitel estabilished BP target values in different subgroups of hypertensive patients [127].

The SPRINT and the ACCORD trials are summarize in Table 2.

\section{Blood pressure (un)control? Time for development of algorithms}

Despite the increased number of cross-sectional and longitudinal studies, International Guidelines and expert consensus paper, the majority of hypertensive subjects present uncontrolled hypertension [2]. As we mentioned in the introduction of this review, a critical role is probably attributable to population aging and to the increase in obesity. However, is important to stress some consideration. First, the National Health and Nutrition Evaluation Survey (NHANES) showed that the overall prevalence of uncontrolled hypertension was $12.8 \%$. Further, $81.5 \%$ of those with AH are aware they have it, and $74.9 \%$ are being treated. In addition, only $52.5 \%$ are under control, with significant variation across different patient subgroups [128]. Of those with uncontrolled hypertension, $89.4 \%$ reported having a usual source of healthcare, and $85.2 \%$ reported having health insurance. Second, the direct and indirect costs of $\mathrm{AH}$ are enormous, considering subjects and their families impacted and the healthcare money spent on treatment of BP complications [128]. Obtaining an adequate BP control at a population level has remained a challenge. Too often the healthcare provider, who visits of the hypertensive subjects, prescribe an inappropriate antihypertensive therapy. Too often, the hypertension specialist visits essential uncomplicated hypertensive subjects instead subjects with true resistant or secondary hypertension. It is time for an adequate hypertension knowledge at the level of community general medicine. To obtain this, system-level approaches and evidencebased management algorithms can help to standardize the treatment. A virtuous example was the Kaiser Permanente Northern California, a regional American hypertension program which involved a population of 3 million subjects [129]. With a system-level method, this program provided an electronic hypertension registry, tracked hypertensive with regular feedback to providers, developed an evidence based algorithm, promoted single-pill combination therapy, used medical assistants for 
follow-up BP checks. The result was a method that facilitates the physician in its therapeutic management and helped the patient in therapeutic adherence. Between 2001 and 2009 the number of subjects with $\mathrm{AH}$ increased by $100 \%$, but hypertensive subjects meeting target BP goals improved from $44 \%$ to $80 \%$, improved to more than $87 \%$ in 2011 [129]. Also the very recent SPRINT trial showed that a large number of subjects can reach the therapeutic target with treatment algorithms and careful monitoring, even with only two or three medicines ("control" and “intensive” group, respectively [122].

Also based on these data, the authors believe that the future of BP control will be based on a systematic approach with evidence based algorithms and a multifactorial coordination that help healthcare provider in the management of hypertensive subjects. The final step of an algorithm which provides simple and complete informations on $\mathrm{AH}$ management, in case the healthcare provider has properly executed all the algorithm steps but elevated BP levels perist, must be the visit of an hypertension specialist. In this way, the hypertension specialist would treat only patients with resistant or refractory hypertension, or, in any case, with BP levels complex to control. The global result is a better population BP control, a reduction in BP complications, a reduction in healthcare cost.

\section{Conclusions}

Hypertension is the major risk factors in the world for CV and all-cause mortality. Further studies are needed to better understand its complex pathogenesis. The clinician to obtain a BP control for the individual patient should consider several factors such as age, lifestyle, the presence of other risk factors, presence of TOD. Further, recent data showed that start earlier and lower as soon as possible BP values reduce the risk. The combination therapy could be a good strategy to obtain this. Finally, a system level approach to the management of hypertension with the avoid of evidence based algorithms seems to be the best strategy to obtain a good BP control at a population level. 


\section{Figure legend}

The pathogenesis of hypertension involves several factors such as genetic factors, inadequate lifestyle, SNS and RAS overactivation, inflammation, large artery stiffness, small vessels resistance which interact each other in the genesis of hypertension. 


\section{References}

1. Ruilope LM. Current challenges in the clinical management of hypertension. Nat Rev Cardiol 2011; 9: 267-75.

2. Rahimi K, Emdin CA, MacMahon S. The epidemiology of blood pressure and its worldwide management. Circ Res 2015; 116: 925-36.

3. Mancia G, Fagard R, Narkiewicz K, et al. 2013 ESH/ESC Guidelines for the management of arterial hypertension: the Task Force for the management of arterial hypertension of the European Society of Hypertension (ESH) and of the European Society of Cardiology (ESC). J Hypertens 2013; 31: 1281-1357.

4. James PA, Oparil S, Carter BL, et al. 2014 evidence-based guideline for the management of high blood pressure in adults: report from the panel members appointed to the Eighth Joint National Committee (JNC 8). JAMA 2014; 311: 507-20.

5. National Institute for Health and Clinical Excellence: Guidance. Hypertension: The Clinical Management of Primary Hypertension in Adults: Update of Clinical Guidelines 18 and 34 [Internet]. London: Royal College of Physicians (UK); 2011.

6. Daskalopoulou SS, Rabi DM, Zarnke KB, et al. The 2015 Canadian Hypertension Education Program recommendations for blood pressure measurement, diagnosis, assessment of risk, prevention, and treatment of hypertension. Can J Cardiol 2015; 31: 54968.

7. Siu AL. Screening for High Blood Pressure in Adults: U.S. Preventive Services Task Force Recommendation Statement. Ann Intern Med 2015 Oct 13. doi: 10.7326/M15-2223.

8. Lewington S, Clarke R, Qizilbash N, Peto R, Collins R; Prospective Studies Collaboration. Age-specific relevance of usual blood pressure to vascular mortality: a meta-analysis of individual data for one million adults in 61 prospective studies. Lancet 2002; 360: 1903-13. 
9. Haider AW, Larson MG, Franklin SS, Levy D; Framingham Heart Study. Systolic blood pressure, diastolic blood pressure, and pulse pressure as predictors of risk for congestive heart failure in the Framingham Heart Study. Ann Intern Med 2003; 138: 10-6.

10. Swaminathan RV, Alexander KP. Pulse pressure and vascular risk in the elderly: associations and clinical implications. Am J Geriatr Cardiol 2006; 15: 226-32.

11. Kupper N, Ge D, Treiber FA, Snieder H. Emergence of novel genetic effects on blood pressure and hemodynamics in adolescence: the Georgia Cardiovascular Twin Study. Hypertension 2006; 47: 48-54.

12. Sciarrone MT, Stella P, Barlassina C, et al. ACE and alpha-adducin polymorphism as markers of individual response to diuretic therapy. Hypertension 2003; 41: 398-403.

13. International Consortium for Blood Pressure Genome-Wide Association Studies. Genetic variants in novel pathways influence blood pressure and cardiovascular disease risk. Nature 2011; 478: 103-9.

14. Huan T, Esko T, Peters MJ, et al. A meta-analysis of gene expression signatures of blood pressure and hypertension. PLoS Genet 2015 Mar 18; 11:e1005035.

15. Phillips MI, Kimura B. Gene therapy for hypertension: antisense inhibition of the reninangiotensin system. Methods Mol Med 2005; 108: 363-79.

16. Frost CD, Law MR, Wald NJ. By how much does dietary salt reduction lower blood pressure? II-Analysis of observational data within populations. BMJ 1991; 302: 815-8.

17. Kotchen TA, Cowley AW Jr, Frohlich ED. Salt in health and disease - a delicate balance. N Eng J Med 2013; 368: 1229-37.

18. INTERSALT Study: an international co-operative study on the relation of blood pressure to electrolyte excretion in populations. I. Design and methods. The INTERSALT Co-operative Research Group. J Hypertens 1986; 4: 781-7. 
19. Zhou BF, Stamler J, Dennis B, et al. Nutrient intakes of middle-aged men and woman in China, Japan, United Kingdom, and United States in the late 1990s: the INTERMAP study. J Hum Hypertens 2003; 17: 623-30.

20. Mente A, O’Donnel MJ, Rangarajan S, et al. Association of urinary sodium and potassium excretion with blood pressure. N Eng J Med 2014; 371: 601-11.

21. Weinberger MH, Fineberg NS, Fineberg SE, Weinberger M. Salt sensitivity, pulse pressure, and death in normal and hypertensive humans. Hypertension 2001; 37: 429-32.

22. THOP Investigators. Effects of weight loss and sodium reduction intervention on blood pressure and hypertensive incidence in overweight people with high-normal blood pressure. The Trials of Hypertension Prevention, phase II. The Trials of Hypertension Prevention Collaborative Research Group. Arch Intern Med 1997; 157: 657-67.

23. O’Donnel MJ, Mente A, Smyth A, Yusuf S. Salt intake and cardiovascular disease: why are data inconsistent? Eur Heart J 2013; 34: 1034-40.

24. Hall JE. The Kidney, hypertension and obesity. Hypertension 2003; 41: 625-33.

25. Jones DW, Kim JS, Andrew ME, Kim SJ, Hong YP. Body mass index and blood pressure in Korean men and women: the Korean National Blood Pressure Survey. J Hypertens 1994; 12: $1433-7$.

26. Garrison RJ, Kannel WB, Stokes J III, Castelli WP. Incidence and precursor of hypertension in young adults: the Framingham Offspring Study. Prev Med 1987; 16: 235-51.

27. Stevens VJ, Obarzanek E, Cook NR, et al. Trials for the Hypertension Prevention Research Group. Long-term weight loss and changes in blood pressure: results of the Trials of Hypertension Prevention, phase II. Ann Intern Med 2001; 134: 1-11.

28. Tchernof A, Després JP. Pathophysiology of human visceral obesity: an update. Physiol Rev 2013; 93: 359-404.

29. Hall ME, do Carmo JM, da Silva AA, Juncos LA, Wang Z, Hall JE. Obesity, hypertension, and chronic kidney disease. Int J Nephrol Renovasc Dis 2014; 7: 75-88. 
30. Hall JE, da Silva AA, do Carmo JM, et al. Obesity-induced hypertension: role of sympathetic nervous system, leptin, and melanocortins. J Biol Chem. 2010; 285: 1721-6.

31. Lohmeier TE, Iliescu R. The sympathetic nervous system in obesity hypertension. Curr Hypertens Rep 2013; 15: 409-16.

32. Hall JE, Henegar JR, Dwyer TM, et al. Is obesity a major cause of chronic kidney disease? Adv Ren Replace Ther 2004; 11: 41-54.

33. Hall ME, do Carmo JM, da Silva AA, Juncos LA, Wang Z, Hall JE. Obesity, hypertension, and chronic kidney disease. Int J Nephrol Renovasc Dis 2014; 7: 75-88.

34. Hottigoudar RU, Gopinathannair R. Inappropriate' sinus tachycardia: does the 100 beats per min cut-off matter? Future Cardiol 2013; 9: 273-88.

35. Mancia G, Grassi G. The autonomic nervous system and hypertension. Circ Res 2014; 114 : 1804-14.

36. Grassi G, Mark A, Esler M. The sympathetic nervous system alterations in human hypertension. Circ Res 2015; 116: 976-90.

37. Muszkat M, Kurnik D, Sofowora GG, Wood AJ, Stein CM. Independent regulation of $\alpha 1$ and $\alpha 2$ adrenergic receptor-mediated vasoconstriction in vivo. J Hypertens 2011; 29: 251-6.

38. Adefurin A, Ghimire LV, Kohli U, et al. Blacks have a greater sensitivity to a1adrenoceptor-mediated venoconstriction compared with whites. Hypertension 2013; 61: 915-20.

39. Serravalle G, Lonati L, Buzzi S, et al. Sympathetic nerve traffic and baroreflex function in optimal, normal and high-normal blood pressure states. J Hypertens 2015; 33: 1411-7.

40. Greenwood JP, Scott EM, Stoker JB, Mary DA. Hypertensive left ventricular hypertrophy: relation to peripheral sympathetic drive. J Am Coll Cardiol 2001; 38: 1711-7.

41. Grassi G, Serravalle G, Quarti-Trevano F, et al. Sympathetic and baroreflex cardiovascular control in hypertension-related left ventricular dysfunction. Hypertension 2009; 53: 205-9. 
42. Grassi G, Serravalle G, Mancia G. Sympathetic activation in cardiovascular disease: evidence, clinical impact and therapeutic implications. Eur J Clin Invest 2015 Oct 19. doi: 10.1111/eci.12553. [Epub ahead of print]

43. Pende A, Dallegri F. Renin-angiotensin antagonists: therapeutic effects beyond blood pressure control? Curr Pharm Des 2012; 18 :1011-20.

44. Kaschina E, Lauer D, Schmerler P, Unger T, Steckelings UM. AT2 receptors targeting cardiac protection post-myocardial infarction. Curr Hypertens Rep 2014; 16: 441.

45. Mann SJ. Drug therapy for resistant hypertension: simplifying the approach. J Clin Hypertens (Greenwich) 2011; 13: 120-30.

46. Smith SM, Campbell JD. Cost-effectiveness of renin-guided treatment of hypertension. Am J Hypertens 2013; 26:1303-10.

47. Wagenseil JE, Mecham RP. Elastin in large artery stiffness and hypertension. J Cardiovasc Transl Res 2012; 5: 264-73.

48. O'Rourke MF, Nichols WW. Aortic diameter, aortic stiffness, and wave reflection increase with age and isolated systolic hypertension. Hypertension 2005; 45: 652-8.

49. Van Bortel LM, Laurent S, Boutouyrie P, et al. Expert consensus document on the measurement of aortic stiffness in daily practice using carotid-femoral pulse wave velocity. J Hypertens 2012; 30: 445-8.

50. Mitchell GF. Arterial stiffness and hypertension: chicken or egg? Hypertension 2014; 64: $210-4$

51. Kaess BM, Rong J, Larson MG, et al. Aortic stiffness, blood pressure progression, and incident hypertension. JAMA 2012; 308: 875-81.

52. Reference Values for Arterial Stiffness Collaboration. Determinants of pulse wave velocity in healthy people and in the presence of cardiovascular risk factors: 'establishing normal and reference values. Eur Heart J 2010; 31: 2338-50. 
53. Laurent S, Boutouyrie P, Asmar R, et al. Aortic stiffness is an independent predictor of allcause and cardiovascular mortality in hypertensive patients. Hypertension 2001; 37: 12361241.

54. Vlachopoulos C, Aznaouridis K, Stefanadis C. Aortic stiffness for cardiovascular risk prediction: just measure it, just do it! J Am Coll Cardiol 2014; 63: 647-9.

55. Nichols WW, O'Rourke MF. McDonald's Blood Flow in Arteries; Theoretical, Experimental and Clinical Principles. 6th ed. London: Hodder Arnold; 2011:755.

56. Rizzoni D, Agabiti-Rosei E. Structural abnormalities of small resistance arteries in essential hypertension. Intern Emerg Med 2012; 7: 205-12.

57. Muiesan ML, Salvetti M, Rizzoni D, et al. Pulsatile hemodynamics and microcirculation: evidence for a close relationship in hypertensive patients. Hypertension 2013; 61: 130-6.

58. Sharman JE, Laurent S. Central blood pressure in the management of hypertension: soon reaching the goal? J Hum Hypertens 2013; 27: 405-11.

59. Herbert A, Cruickshank JK, Laurent S, Boutouyrie P; Reference Values for Arterial Measurements Collaboration. Establishing reference values for central blood pressure and its amplification in a general healthy population and according to cardiovascular risk factors. Eur Heart J 2014; 35: 3122-33.

60. McEniery CM, Cockcroft JR, Roman MJ, Franklin SS, Wilkinson IB. Central blood pressure: current evidence and clinical importance. Eur Heart J 2014; 35: 1719-25.

61. Williams B, Lacy PS, Thom SM, et al. Differential impact of blood pressure-lowering drugs on central aortic pressure and clinical outcomes: principal results of the Conduit Artery Function Evaluation (CAFE) study. Circulation 2006; 113: 1213-25.

62. Vlachopoulos C, Aznaouridis K, Stefanadis C. Prediction of Cardiovascular Events and AllCause Mortality With Arterial Stiffness. J Am Coll Cardiol 2010; 55: 1318-27. 
63. Sharman JE, Marwick TH, Gilroy D, et al. Randomized trial of guiding hypertension management using central aortic blood pressure compared with best-practice care: principal findings of the BP GUIDE study. Hypertension 2013; 62: 1138-45.

64. Kollias A, Lagou S, Zeniodi ME, Boubouchairopoulou N, Stergiou GS. Association of Central Versus Brachial Blood Pressure With Target-Organ Damage. Hypertension 2015 nov 23;. DOI: 10.1161/HYPERTENSIONAHA.115.06066.

65. Montecucco F, Pende A, Quercioli A, Mach F. Inflammation in the pathophysiology of essential hypertension. J Nephrol 2011; 24: 23-34

66. Vinh A, Chen W, Blinder Y, et al. Inhibition and genetic ablation of the B7/CD28 T-cell costimulation axis prevents experimental hypertension. Circulation. 2010; 122: 2529-37.

67. Kirabo A, Fontana V, de Faria AP, et al. DC isoketal-modified proteins activate T cells and promote hypertension. J Clin Invest 2014; 124: 4642-56.

68. Wenzel P, Knorr M, Kossmann S, et al. Lysozyme M-positive monocytes mediate angiotensin II-induced arterial hypertension and vascular dysfunction. Circulation 2011; 124: $1370-81$

69. McMaster WG, Kirabo A, Madhur MS, Harrison DG. Inflammation, immunity, and hypertensive end-organ damage. Circ Res 2015; 116: 1022-33.

70. Chatterjee M, Saluja R, Tewari S, Barthwal MK, Goel SK, Dikshit M. Augmented nitric oxide generation in neutrophils: oxidative and pro-inflammatory implications in hypertension. Free Radic Res 2009; 43: 1195-204.

71. Liu X, Zhang Q, Wu H, et al. Blood Neutrophil to Lymphocyte Ratio as a Predictor of Hypertension. Am J Hypertens 2015; 28: 1339-46.

72. Shimbo D, Abdalla M, Falzon L, Townsend R, Muntner P. Role of Ambulatory and Home Blood Pressure Monitoring in Clinical Practice: A Narrative Review. Ann Intern Med 2015; 163: 691-700. 
73. Pringle E, Phillips C, Thijs L, et al. Systolic blood pressure variability as a risk factor for stroke and cardiovascular mortality in the elderly hypertensive population. J Hypertens 2003; 21: 2251-7.

74. Dolan E, Stanton A, Thijs L, et al. Superiority of ambulatory over clinic blood pressure measurement in predicting mortality: the Dublin outcome study. Hypertension 2005; 46: $156-61$.

75. Sega R, Facchetti R, Bombelli M, et al. Prognostic value of ambulatory and home blood pressures compared with office blood pressure in the general population: follow-up results from the Pressioni Arteriose Monitorate e Loro Associazioni (PAMELA) study. Circulation 2005; 111: 1777-83.

76. Palatini P, Reboldi G, Beilin LJ, et al. Added predictive value of night-time blood pressure variability for cardiovascular events and mortality: the Ambulatory Blood PressureInternational Study. Hypertension 2014; 64: 487-93.

77. Stergiou GS, Asayama K, Thijs L, et al. Prognosis of white-coat and masked hypertension: International Database of HOme blood pressure in relation to Cardiovascular Outcome. Hypertension 2014; 63: 675-82.

78. Angeli F, Reboldi G, Verdecchia P. Masked hypertension: evaluation, prognosis, and treatment. Am J Hypertens 2010; 23: 941-8.

79. Dahlöf B, Devereux RB, Kjeldsen SE, et al. Cardiovascular morbidity and mortality in the Losartan Intervention For Endpoint reduction in hypertension study (LIFE): a randomised trial against atenolol. Lancet 2002; 359: 995-1003.

80. Julius S, Kjeldsen SE, Weber M, et al. Outcomes in hypertensive patients at high cardiovascular risk treated with valsartan- or amlodipine-based regimens: VALUE, a randomised trial. Lancet 2004; 363: 2021-31

81. Dahlöf B, Sever PS, Poulter NR, et al. Prevention of cardiovascular events with an antihypertensive regimen of amlodipine adding perindopril as required versus atenolol 
adding bendroflumethiazide as required, in the Anglo-Scandinavian Cardiac Outcomes Trial-Blood Pressure Lowering Arm (ASCOT-BPLA): a multicentre randomised controlled trial. Lancet 2005; 366: 895-906.

82. Jamerson K, Weber MA, Bakris GL, et al. Benazepril plus amlodipine or hydrochlorothiazide for hypertension in high-risk patients. N Engl J Med 2008; 359: $2417-$ 28.

83. Swedberg K, Komajda M, Böhm M, et al. Effects on outcomes of heart rate reduction by ivabradine in patients with congestive heart failure: is there an influence of beta-blocker dose?: findings from the SHIFT (Systolic Heart failure treatment with the I(f) inhibitor ivabradine Trial) study. J Am Coll Cardiol 2012; 59: 1938-45.

84. Artom N, Montecucco F, Mach F, Dallegri F, Pende A. Angiotensin II receptor antagonists in acute coronary syndromes. Eur J Clin Invest 2014; 44: 219-30.

85. Williams B, MacDonald TM, Morant S, et al. Spironolactone versus placebo, bisoprolol, and doxazosin to determine the optimal treatment for drug-resistant hypertension (PATHWAY-2): a randomised, double-blind, crossover trial. Lancet 2015 Sep 18. pii: S0140-6736(15)00257-3. doi: 10.1016/S0140-6736(15)00257-3. [Epub ahead of print]

86. Taddei S. Combination therapy in hypertension: what are the best options according to clinical pharmacology principles and controlled clinical trial evidence? Am J Cardiovasc Drugs 2015; 15: 185-94.

87. Volpe M, Tocci G. Rationale for triple fixed-dose combination therapy with an angiotensin II receptor blocker, a calcium channel blocker, and a thiazide diuretic. Vasc Health Risk Manag 2012; 8: 371-80.

88. Corrao G, Parodi A, Zambon A, et al. Reduced discontinuation of antihypertensive treatment by two-drug combination as first step. Evidence from daily life practice. J Hypertens 2010; 28: 1584-90. 
89. Gradman AH, Parisé H, Lefebvre P, Falvey H, Lafeuille MH, Duh MS. Initial combination therapy reduces the risk of cardiovascular events in hypertensive patients: a matched cohort study. Hypertension 2013; 61: 309-18.

90. Myat A, Redwood SR, Quershi AC, Spertus JA, Williams B. Resistant hypertension. BMJ 2012; 345: e7473.

91. Laurent S, Schlaich M, Esler M. New drugs, procedures, and devices for hypertension. Lancet 2012; 380: 591-600.

92. Corrao G, Parodi A, Nicotra F, et al. Better compliance to antihypertensive medications reduces cardiovascular risk. J Hypertens 2011; 29:610-8.

93. Kronish IM, Woodward M, Sergie Z, Ogedegbe G, Falzon L, Mann DM. Meta-analysis: impact of drugs class on adherence to antihypertensives. Circulation 2011; 123: 1611-1621.

94. Nuesch R, Schroeder K, Dieterle T, et al. Relation between insufficient response to antihypertensive treatment and poor compliance with treatment: a prospective case-control study. BMJ 2001; 323: 142-6.

95. Iriarte G, Gonzales O, Ferreiros N, Maguregui MI, Alonso RM, Jimenez RM. Validation of a fast liquid chromatography-UV method for the analysis of drugs used in combined cardiovascular therapy in human plasma. J Chromatogr B Analyt Technol Biomed Life Sci 2009; 877: 3045-53.

96. Gonzales O, Iriate G, Rico E, et al. LC-MS/MS method for the determination of several drugs used in combined cardiovascular therapy in human plasma. J Chromatogr B Analyt Technol Biomed Life Sci 2010; 878:2685-2692.

97. Burnier M, Santschi V, Favrat B, Brunner HR. Monitoring compliance in resistant hypertension: an important step in patient management. J Hypertens Suppl 2003; 21:s37-42.

98. Strauch B, Petràk O, Zelinka T, et al. Precise assessment of noncompliance with the antihypertensive therapy in patients with resistant hypertension using toxicological serum analysis. J Hypertens 2013; 31: 2455-61. 
99. Jung O, Gechter JL, Wunder C, et al. Resistant hypertension? Assessment of adherence by toxicological urine analysis. J Hypertens 2013; 31: 766-74.

100. Tomaszewski M, White C, Patel P. High rates of non-adherence to antihypertensive treatment revealed by high-performance liquid chromatography-tandem mass spectrometry (HP LC-MS/MS) urine analysis. Heart 2014; 100: 855-61.

101. Corti R, Burnett JC Jr, Rouleau JL, Ruschitzka F, Luscher TF. Vasopeptitase inhibitors: a new therapeutic concept in cardiovascular disease? Circulation 2001; 104: 1856-62.

102. Bevan EG, Connell JM, Doyle J, et al. Candoxatril, a neutral endopeptidase inhibitor: efficacy and tolerability in essential hypertension. J Hypertens 1992; 10: 607-613.

103. von Lueder TG, Sangaralingham SJ, Wang BH, et al. Renin-angiotensin blockade combined with natriuretic peptide system augmentation: novel therapeutic concepts to combat heart failure. Circ Heart Fail 2013; 6: 594-605.

104. McMurray JJ, Packer M, Desai AS, et al. Dual Angiotensin receptor and neprilysin inhibition as an alternative to angiotensin-converting enzyme inhibition in patients with chronic systolic heart failure: rationale for and design of the Prospective comparison of ARNI with ACEI to Determine Impact on Global Mortality and morbidity in Heart Failure trial (PARADIGM-HF). Eur J Heart Fail 2013; 15: 1062-73.

105. McMurray JJ, Packer M, Desai AS, et al. Angiotensin-neprilysin inhibition versus enalapril in heart failure. N Eng J Med 2014; 371: 993-1004.

106. Fala L. Entresto (Sacubitril/Valsartan): First-in-Class Angiotensin Receptor Neprilysin Inhibitor FDA Approved for Patients with Heart Failure. Am Health Drug Benefits 2015;8: 330-4.

107. Krum H, Schlaich M, Withbourn R. Catheter-based renal sympathetic denervation for resistant hypertension: a multicenter safety and proof-of-principle cohort study. Lancet 2009; 373: 1275-81. 
108. Symplicity HTN-2 Investigators, Esler MD, Krum H et al. Renal sympathetic denervation in patients with treatment-resistant hypertension (The Symplicity HTN-2 trial): a randomized controlled trial. Lancet 2010; 376: 1903-9.

109. Krum H, Schlaich MP, Sobotka PA. Percutaneous renal denervation in patients with treatment-resistant hypertension: final 3-year report of the Symplicity HTN-1 study. Lancet 2014; 383: 622-9.

110. Esler MD, Bohm M, Sievert H. Catheter-based renal denervation for treatment of patients with treatment-resistant hypertension: 36 month results from the SYMPLICITY HTN-2 randomized clinical trial. Eur Heart J 2014; 35: 1752-9.

111. Persu A, Renkin J, Thijs L, Staessen JA. Renal denervation: ultima ratio or standard in treatment-resistant hypertension. Hypertension 2012; 60: 596-606.

112. Bhat DL, Kandzari DE, O’Neill WW, et al. A controlled trial of renal denervation for resistant hypertension. N Engl J Med 2014; 370: 1393-401.

113. Rosa J, Widimský P, Toušek $\mathrm{P}$, et al. Randomized comparison of renal denervation versus intensified pharmacotherapy including spironolactone in true-resistant hypertension: six-month results from the Prague-15 study. Hypertension 2015; 65: 407-13.

114. Scheffers IJ, Kroon AA, Schmidli J, et al. Novel baroreflex activation therapy in resistant hypertension: results of a European multi-center feasibility study. J Am Coll Cardiol 2010; 56: 1254-8.

115. Hoppe UC, Brandt MC, Watcher R, et al. Minimally invasive system for baroreflex activation therapy chronically lowers blood pressure with pacemaker-like safety profile: results from the Barostim neo trial. J Am Soc Hypertens 2012; 6: 270-6.

116. Catapano AL, Reiner Z, De Backer G, et al. ESC/EAS Guidelines for the management of dyslipidaemias The Task Force for the management of dyslipidaemias of the European Society of Cardiology (ESC) and the European Atherosclerosis Society (EAS). Atherosclerosis 2011; 217: 3-46. 
117. Stone NJ, Robinson JG, Lichtenstein AH, et al. 2013 ACC/AHA guideline on the treatment of blood cholesterol to reduce atherosclerotic cardiovascular risk in adults: a report of the American College of Cardiology/American Heart Association Task Force on Practice Guidelines. J Am Coll Cardiol 2014; 63: 2889-934.

118. Blood Pressure Lowering Treatment Trialists' Collaboration, Sundström J, Arima H, Woodward M, et al. Blood pressure-lowering treatment based on cardiovascular risk: a meta-analysis of individual patient data. Lancet 2014; 384: 591-8.

119. Thomopoulos C, Parati G, Zanchetti A. Effects of blood pressure lowering on outcome incidence in hypertension: 3. Effects in patients at different levels of cardiovascular risk--overview and meta-analyses of randomized trials. J Hypertens 2014; 32: 2305-14.

120. Struthers AD. A new approach to residual risk in treated hypertension--3P screening. Hypertension 2013; 62: 236-9.

121. Shekelle PG, Rich MW, Morton SC, et al. Efficacy of angiotensin-converting enzyme inhibitors and beta-blockers in the management of left ventricular systolic dysfunction according to race, gender, and diabetic status: a meta-analysis of major clinical trials. J Am Coll Cardiol 2003;41: 1529-38.

122. SPRINT Research Group. A Randomized Trial of Intensive versus Standard BloodPressure Control. N Engl J Med 2015; 373:2103-16.

123. Drazen JM, Morrissey S, Campion EW, Jarcho JA. A SPRINT to the Finish. N Engl J Med. 2015; 373: 2174-5.

124. The ACCORD study group. Outcomes of combined cardiovascular risk factor management strategies in type 2 diabetes: the ACCORD randomized trial. $\mathrm{N}$ Engl $\mathrm{J}$ Med 2010; 362: 1575-85.

125. Berlowitz DR. Hypertension control in the elderly: too much of a good thing? J Clin Hypertens (Greenwich) 2014;16: 265-6. 
126. Messerli FH, Panjrath GS. The J-curve between blood pressure and coronary artery disease or essential hypertension: exactly how essential? J Am Coll Cardiol 2009; 54: 182734.

127. Zanchetti A, Thomopoulos C, Parati G. Randomized controlled trials of blood pressure lowering in hypertension: a critical reappraisal. Circ Res 2015; 116: 1058-73.

128. Sakhuja A, Textor SC, Taler SJ. Uncontrolled hypertension by the 2014 evidencebased guideline: results from NHANES 2011-2012. J Hypertens 2015; 33: 644-51.

129. Go AS, Bauman MA, Coleman King SM, et al. An effective approach to high blood pressure control: a science advisory from the American Heart Association, the American College of Cardiology, and the Centers for Disease Control and Prevention. Hypertension 2014; 63: 878-85. 